\title{
9
}

\section{A RELAÇÃO ENTRE O ESTADO E OS POVOS INDÍGENAS NO BRASIL*}

\author{
Miguel Anacleto da Silva Júnior \\ Yuri Vasconcelos da Silva
}

\section{Introdução}

A denominação "índio", imposta pelo colonizador europeu aos povos do continente americano, além de genérica, denota um componente depreciativo. Desconsidera, por exemplo, a imensa diversidade ancestral, cultural e linguística dos povos indígenas reduzindo-os a um artificial denominador comum. Seria o equivalente a chamar todos os povos europeus de "brancos" ou todos os povos da África subsaariana de "negros". Os povos indígenas constituem um grande número de nações, que embora compartilhem alguns valores comuns, se diferenciam pelos seus hábitos, costumes, ritos, crenças, línguas e formas de organização social.

Tão pernicioso quanto às manifestações preconceituosas contra os povos indígenas, são as formas idílicas e romanceadas presentes, sobretudo, nas camadas médias, que sugerem que todo "índio" é "puro e bom", e que é preciso defendê-los dos vícios da sociedade moderna. Também não é rara a adoção de estereótipos tal como o de exigir trajes tradicionais e adornos para serem considerados "índios de verdade". Essa visão paternalista coincide, embora de forma diferente, com a tutela disfarçada ainda presente na política de estado e em muitas práticas exercidas por várias entidades religiosas e organizações não governamentais.

Como qualquer comunidade humana, os povos indígenas estão sujeitos a mudanças culturais e a interação com os valores das comunidades não índias circundantes, absorvendo, inclusive, recursos tecnológicos de largo uso como os celulares ou a internet. Isso em nada compromete as suas identidades étnicas enquanto reconhecida por eles próprios.

Estimativas recentes, realizadas por pesquisadores e antropólogos, indicam que o número de indígenas existentes no mundo atual está situado entre 250 a 300 milhões de indivíduos, distribuídos em aproximadamente cinco mil grupos distintos, presentes em todos os continentes. Invariavel-

"DOI - 10.29388/978-65-86678-42-0-0-f.205-222 
mente, a história dos povos indígenas está marcada pela violência de vários tipos e dimensões, indo desde o genocídio até as recorrentes tentativas de aniquilar suas culturas e os seus meios de sobrevivência, especialmente no que se relaciona às suas terras e os recursos naturais ali existentes.

Foram submetidos, em sua grande maioria, à brutalidade do colonialismo, matiz de todas as mazelas que afetam ainda hoje esses povos, tais como a perda de suas terras ancestrais, a pobreza, os altos índices de mortalidade infantil, o preconceito, entre outras. Segundo a Organização das Nações Unidas para Alimentação e Agricultura - FAO, os povos indígenas na América Latina sofrem com alguns dos índices mais altos de fome e pobreza da região (FAO, 2018).

A América Latina foi palco de uma sistemática matança de indígenas nos primeiros séculos de colonização. Povos inteiros foram dizimados, tanto pelas armas quanto pelo contágio de doenças desconhecidas pelos nativos. Civilizações avançadas, como a dos Incas, na região andina, ou os Maias e Astecas na América Central, foram completamente destroçadas.

No Brasil, as estimativas feitas pelos estudiosos são bastante díspares, variando entre um e dez milhões de habitantes quando da chegada dos colonizadores. Segundo a Fundação Nacional do Índio (FUNAI), vivem hoje pouco mais de 800 mil indígenas, distribuídos em 305 povos distintos, sendo 69 deles constituídos de grupos isolados ainda não contatados. Eles falam, pelo menos, 274 línguas diferentes (das conhecidas), o que coloca o Brasil como um dos países com maior diversidade étnica e linguística do mundo. A maioria está concentrada na região norte, embora exista um considerável contingente nas regiões nordeste e centro-oeste (FUNAI, 2020a).

Tal como a escravidão, o extermínio de inúmeras nações indígenas ao longo dos últimos cinco séculos constitui uma das páginas mais vergonhosas da história do Brasil, especialmente no Nordeste, onde teve início a colonização propriamente dita. Perseguidos, acossados ou forçados à política de "assimilação" pelos sucessivos governos e pelas classes dominantes, os povos indígenas dessa região estiveram próximos de serem totalmente exterminados.

Todo esse ciclo de perseguição, invasão de terras e tentativas de eliminação física não foram realizados sem que houvesse resistência por parte dos povos indígenas no Brasil, ainda que em completa desvantagem perante o aparato militar dos governos e das elites. Essa resistência foi retomada com maior vigor na segunda metade do século XX, especialmente a partir dos anos 80 . De lá para cá, surgiram várias organizações indígenas tanto de caráter regional como nacional, assim como se multiplicaram as 
organizações da sociedade civil em defesa da chamada causa indígena. Por pressão delas, foi possível obter avanços na Constituição de 1988, ainda que muito distantes do satisfatório.

Por mais que as classes dominantes tentem camuflar, é inegável a influência dos povos indígenas no patrimônio cultural do Brasil, a começar pela infinidade de topônimos de origem indígena até a vertente cultural presente na música, na dança, na culinária e em vários costumes da sociedade brasileira. Para além disso, é preciso observar atentamente as potenciais possibilidades da contribuição dos indígenas nos campos da saúde, alimentação e preservação do meio ambiente.

A presente publicação ${ }^{1}$ representa uma contribuição não apenas para suscitar um debate sobre a chamada questão indígena, mas, sobretudo, uma conclamação para que os/as militantes políticos de nosso país assumam como bandeira a solidariedade com os povos indígenas nas suas lutas cotidianas, a começar pela garantia do acesso e controle de suas terras ancestrais e o seu direito à autodeterminação.

\section{A Relação com o Estado}

Após quatro séculos de uma política exterminatória dos índios no Brasil, o governo federal brasileiro passa a se preocupar na construção de um aparato estatal, responsável pela política indigenista. Vale ressaltar que essa construção surgiu em decorrência das denúncias internacionais como no XVI Congresso de Americanistas em Viena (em 1908), onde o Brasil foi acusado de permitir ou ser omisso sobre os casos de massacre que ocorriam contra os índios - e dos vários conflitos armados envolvendo os índios e as defesas de suas terras, em virtude das diversas frentes de expansão para o interior do país.

Dessa forma, é criado, em 1910, o Serviço de Proteção aos Índios e Localização de Trabalhadores Nacionais, mais tarde apenas denominado Serviço de Proteção aos Índios (SPI). A finalidade do órgão indigenista era não somente a proteção dos indígenas, mas também a sua integração na chamada "civilização". Para gerenciar o novo órgão indigenista foi convidado o então coronel Cândido Mariano da Silva Rondon, uma vez que o mesmo tinha obtido sucesso na instalação de redes telegráficas no interior do país, tendo tido um contato pacífico com as populações indígenas existentes nesse percurso (ISA, 2018).

\footnotetext{
${ }^{1}$ Capítulo baseado, com alterações e atualizações, no texto do livro "Questão Indígena: abordagem para uma nação solidária”. Olinda: Livro Rápido, 2014. 20 p., dos mesmos autores.
} 
A política indigenista foi formalizada no Código Civil de 1916 (BRASIL, 1916) e no Decreto no 5.484 de 1928 (BRASIL, 1928), que estabeleceram o poder de tutela ao SPI, bem como a relativa incapacidade jurídica dos indígenas. Cabe recordar que a primeira Constituição Brasileira, em 1824, ignorava a existência de sociedades indígenas, negando a diversidade étnica e cultural do nosso país. Somente com a Constituição de 1934 que os direitos dos Povos Indígenas começaram a ser tratados nos marcos legais, assegurando aos índios a posse dos seus territórios tradicionais e atribuindo à União a responsabilidade pela promoção da política indigenista.

A política integracionista do SPI entendia o índio como um segmento em estágio transitório à chamada "civilização". Ou seja, havia o reconhecimento do caráter coletivo dos Povos Indígenas, mas como um estágio de desenvolvimento culturalmente inferior, que se concluiria com a incorporação do índio à sociedade nacional. 0 Estado desenvolvia uma política indigenista que criasse as condições para que os índios evoluíssem lentamente, até estarem integrados com a sociedade brasileira. Nesse sentido, negavam-se os costumes, crenças, hábitos e rituais dos Povos Indígenas, numa clara política de homogeneização da cultura brasileira dominante.

É também nesse período que ganha grande publicidade a atuação dos irmãos Villas Bôas. Reconhecidos como humanistas, eles criaram, em 1961, o Parque Indígena do Xingu - a primeira terra indígena homologada pelo governo federal -, com a finalidade de proteger diversos grupos (16 etnias vivem no parque) do contato com a cultura dos grandes centros urbanos, sendo, portanto, um trabalho de preservação da diversidade cultural, onde os indígenas pudessem manter os seus modos tradicionais de organização social e de subsistência econômica.

Apesar da boa intencionalidade dos irmãos Villas Bôas, entendemos que a construção do Parque significou também o aprisionamento das nações indígenas, uma vez que unificou em um mesmo território, diferentes etnias, com línguas e culturas distintas. Visto que a proposta inicial dos irmãos Villas Bôas para o Parque previa limites muito maiores do que os vigentes nos dias de hoje - que excluiu as cabeceiras dos principais rios, que hoje estão circundadas por cidades e pastagens que ameaçam a vida das populações indígenas que habitam no Parque -, é de se supor que o real interesse na construção do Parque pelas autoridades governamentais da época não foi a preservação da diversidade cultural, mas a retirada dos índios dos seus territórios tradicionais para o desenvolvimento da economia capitalista no meio rural. 
Pode-se dizer que o Serviço de Proteção aos Índios (SPI) alterou o quadro da gestão indígena no Brasil, fazendo com que a hegemonia da Igreja Católica (catequese) passasse a coexistir com a política de proteção por parte do Estado, realizando o atendimento à saúde, evitando o massacre exterminatório das comunidades indígenas e proporcionando uma educação formal a esses Povos. O surgimento do SPI também significou uma centralização da política indigenista, uma vez que diminuiu o papel que os estados realizavam em relação aos indígenas.

Essa foi a tônica do primeiro momento da política indigenista por parte do Estado brasileiro: o não reconhecimento dos índios como povos diferenciados; a política de assimilação cultural; e a incapacidade de assegurar a proteção territorial dos Povos Indígenas, uma vez que continuavam constantes as invasões às Terras Indígenas, motivadas pelos interesses econômicos das classes dominantes em nosso país.

Para além dessas questões, no final da década de 1950 e início dos anos 1960, o SPI passou a sofrer inúmeras denúncias de improbidade administrativa, de genocídio e de saques das terras e das riquezas das aldeias pelos próprios agentes do governo, repercutindo, nacional e internacionalmente, uma imagem negativa do órgão estatal. Dessa forma, o golpe civilmilitar, implementado em nosso país no ano de 1964, extingue o SPI e o substitui, em 1967, pela Fundação Nacional do Índio (FUNAI).

Durante o período militar, relatos revelam uma política de Estado de extermínio sistemático das Aldeias Indígenas. 0 propósito do regime ditatorial era dizimar comunidades indígenas localizadas em áreas concedidas para grandes latifundiários e companhias internacionais, com a finalidade de executar grandes empreendimentos, como a transamazônica. Para essa finalidade, os militares utilizavam a repressão, violência, trabalho escravo, estupros, torturas e incontáveis crueldades contra as tribos brasileiras. Esses métodos provocaram a redução de vários Territórios Indígenas, além da expropriação das riquezas de suas terras.

A ditadura construiu e treinou a Guarda Rural Indígena (Grin), ensinando técnicas de tortura e enraizando a violência policial nas terras indígenas, obrigando os índios a massacrarem o seu próprio povo. Em 1969, objetivando o controle dos indígenas, foi construído o Reformatório krenak (assim chamado por ficar em terras dos índios krenak), funcionando como colônia penal para os índios que transgrediam as ordens ditadas em seu território de origem, como se recusar a sair de suas terras tradicionais.

Além dessas questões, a ditadura obrigava muitas Aldeias Indígenas a combater os grupos guerrilheiros que lutavam pela democratização em 
nosso país. E aqueles que não participavam das ações militares eram reprimidos e até mortos. Assim, os índios eram obrigados a identificar acampamentos das guerrilhas, caçando os lutadores brasileiros com quem, muitas vezes, já tinham estabelecido contato e relação de amizade.

As políticas indigenistas estatais foram completamente subordinadas aos planos de defesa nacional, com cooptação de lideranças indígenas, limitação de acesso de pesquisadores e organizações de apoio às terras indígenas, além das políticas de construção de estradas e hidrelétricas, expansão de fazendas e extração de minérios.

A FUNAI, criada com o propósito de superar as limitações do antigo SPI, acabou por reproduzi-las, estando sua atuação marcada pela política assimilacionista, paternalista, assistencialista e pelas redes de relações pessoais e corporativas que permearam o seu âmbito interno. O Estatuto do Índio (Lei no 6.001), aprovado em 1973, e ainda vigente, reafirmou as premissas de integração que permearam a história do SPI (BRASIL, 1973).

No início da década de 1980, no chamado período de "redemocratização", a questão indígena voltou a ter uma maior publicidade e repercussão nacional. Ocorrem, nesse período, várias manifestações indígenas e constituições das primeiras organizações formais de base comunitária ou regional.

Com esse cenário, a Constituição de 1988, rompendo com a política assimilacionista e integracionista, reconhece, em seu Artigo 231, o direito dos indígenas à diferença e garante o usufruto exclusivo de seus territórios tradicionalmente ocupados, definidos a partir de seus usos, costumes e tradições (BRASIL, 1988). É nesse período também que as organizações indígenas se consolidam e se fortalecem, forçando a Constituição a reconhecer, através do Artigo 232, as mesmas como legítimas para defender os seus direitos e interesses (BRASIL, 1988).

Essas medidas constitucionais foram extremamente importantes para superar os conceitos de tutela e de "capacidade relativa dos silvícolas", conforme apontava o Código Civil, em 1916 (BRASIL, 1916). Entretanto, esses avanços não se fizeram sentir na prática. A implementação e intensificação das políticas neoliberais em nosso país, a partir da década de 1990, aprofundaram o descaso do Estado brasileiro com as populações indígenas. 


\section{Política neoliberal e os povos indígenas}

A política neoliberal no Brasil começou a ser implementada no governo Collor, se intensificou no governo FHC e é continuada nos governos petistas (Lula e Dilma). Seguindo à risca as recomendações da Cartilha Neoliberal, esses governos trabalharam no sentido de minimizar a participação do Estado na economia do país; privatizar as empresas estatais; aumentar a produção, na perspectiva desenvolvimentista; fragmentar a classe trabalhadora e precarizar as condições de trabalho; dentre outras medidas.

No âmbito indígena, ocorre uma fragmentação das responsabilidades da FUNAI. A saúde, educação, desenvolvimento rural e meio ambiente, anteriormente na responsabilidade do órgão indigenista, passam a fazer parte das atividades dos Ministérios da Saúde, Educação, Desenvolvimento Agrário e Meio Ambiente, respectivamente. Com esse esvaziamento de suas atribuições, a FUNAI passa a se concentrar nas políticas de regularização fundiária, mantendo as limitações evidenciadas em toda história do indigenismo oficial. Os servidores da FUNAI sofrem com o sucateamento ainda maior do órgão indigenista, com péssimas condições de trabalho e o arrocho salarial da década de 1990.

Com a extinção do Ministério do Interior, a FUNAI passa a fazer parte do Ministério da Justiça. Parlamentares contrários aos direitos indígenas tentam extinguir a FUNAI, sem substituí-la por nada, criando um vazio na representação institucional específica dos Povos Indígenas. Os movimentos indígenas, em crescente fortalecimento desde a década de 1980, conseguem frear essa tentativa de aniquilamento da FUNAI. Para os indígenas, apesar das limitações da instituição, era importante mantê-la, reestruturando o órgão indigenista ao mesmo tempo em que se avançasse na reformulação do Estatuto do Índio, datado de 1973. Apesar da criação, em 1991, de uma Comissão Especial para rever o Estatuto do Índio - discutindo temáticas como a proteção territorial, a demarcação de terras indígenas e a situação jurídica dos índios -, os trabalhos foram paralisados em 1994, não alterando o caráter integracionista do retrógrado Estatuto.

Nesse período, os movimentos indígenas se somam aos mais variados movimentos camponeses do país, em luta contra o monopólio capitalista da terra. Os seguidos governos brasileiros - FHC, Lula e Dilma - mantêm uma política de priorização do agronegócio, com grandes repasses aos grandes proprietários de terra, em detrimento de uma política seriamente comprometida com a democratização do meio rural, da reforma agrária, dos territórios indígenas e quilombolas. 
A política de favorecimento ao agronegócio significa uma intensificação da concentração de terra, da destruição ambiental, com uso de transgênicos e agrotóxicos, e dos impactos sociais e culturais de grave expressão, visto as constantes expulsões dos indígenas, quilombolas, ribeirinhos e pequenos agricultores das suas terras, para oportunizar a produção para a exportação.

Esse cenário do meio rural brasileiro traz sérias consequências aos Povos Indígenas. Expulsos dos seus territórios, as comunidades indígenas ficam ameaçadas da sua própria existência, visto que a terra para os indígenas, diferentemente dos latifundiários e do agronegócio, não possui interesses puramente econômicos. A terra tem um significado de sustentabilidade, de memória, de cultura e identidade para os Povos Indígenas, condição vital para a reprodução física e cultural desses povos.

Buscando resistir aos processos de expulsão de suas terras, os movimentos indígenas atuam em duas frentes: a pressão para que a FUNAI realize os procedimentos demarcatórios dos Territórios Indígenas e o conflito direto com posseiros, madeireiros, garimpeiros e latifundiários que saqueiam dos seus territórios todas as riquezas do solo e subsolo, além de violentar social e culturalmente os Povos Indígenas. Além dessas duas frentes, o movimento indígena também atua na perspectiva do autorreconhecimento de diversos grupos indígenas que, por pressão externa da sociedade (perseguição, extermínio, preconceito), negaram sua identidade e hoje retomam um movimento de identidade cultural e de aquisição de suas terras.

A luta pela retomada dos Territórios Indígenas é legítima e de fundamental importância para o processo de transformação da realidade rural em nosso país. Entretanto, o Estado burguês brasileiro caracteriza os movimentos indígenas como violentos, vândalos e baderneiros, fazendo coro ao projeto neoliberal de criminalização dos movimentos sociais. Nesse aspecto, é importante destacar o papel de desinformação e manipulação ideológica dos meios de comunicação no Brasil, que atuam enquanto instrumento burguês de difamação da causa indígena. Os assassinatos das lideranças indígenas e a impunidade continuam tendo presença marcante no meio rural brasileiro.

A violência e presença de posseiros nas Terras Indígenas comprometem também as práticas dos seus rituais e tradições culturais. 0 preconceito, a discriminação e o processo de homogeneização da cultura afetam diretamente os Povos Indígenas. Na sociedade burguesa, a tolerância à diversidade étnica é limitada, sendo permissível apenas se a manifestação étnica permanecer submissa aos ditames dos valores dominantes, permanecendo, 
na lógica burguesa, como uma expressão de "inferioridade cultural". A cultura indígena se apresenta como uma ferramenta da contra hegemonia cultural, devendo ser preservada e valorizada.

Por fim, o caráter neoliberal de monopólio capitalista da terra, de criminalização dos movimentos sociais, de homogeneização da cultura e a violência contra os Territórios Indígenas, faz com que inúmeros índios tenham que deixar os seus locais de origem e se deslocar para as grandes periferias das cidades brasileiras. Além do impacto da perda com a terra e com suas tradições e valores culturais, esses índios desaldeados se inserem, precariamente, no modo de produção capitalista das periferias urbanas, aumentando a força de trabalho excedente e as tentativas de inserção no mercado informal. Portanto, ficam vulneráveis à fome, miséria, prostituição, drogas e todas as mazelas orgânicas ao modelo de sociedade capitalista.

\section{A intensificação do conservadorismo no Brasil e a po- lítica indigenista oficial}

Em 2016, o Brasil foi vitimado por um golpe de Estado, tendo como protagonistas os setores mais retrógrados e corruptos do parlamento nacional, articulados com a velha oligarquia brasileira, sempre refratária a qualquer avanço democrático. Independentemente dos julgamentos positivos ou negativos do governo do Partido dos Trabalhadores, o fato é que é inegável que ocorreu uma manobra anticonstitucional para depor a presidente Dilma Rousseff, legitimamente eleita por mais de 54 milhões de brasileiros. 0 pretexto utilizado foi o de irregularidades contabilísticas ("pedaladas fiscais", no jargão político) para ajustar déficits nas contas públicas, uma prática, diga-se de passagem, comum em todos os governos anteriores.

Dentro desse contexto do golpe parlamentar é que se inicia um período de intensificação dos ataques contra os direitos dos povos originários. 0 ilegítimo governo Temer publicou o decreto n. 9.010/2017 (BRASIL, 2017) que, sob a insígnia fantasiosa de "reestruturação", afetou diretamente o direito das populações indígenas brasileiras, uma vez que reduziu bastante a quantidade de unidades da FUNAI e, consequentemente, a sua capacidade de atuação na promoção e proteção dos direitos indígenas.

O sucateamento do órgão indigenista é uma constante nos governos neoliberais, com diminuição do orçamento e um quadro pessoal limitado e em condições de trabalho precárias. Registra-se que durante o governo pe- 
tista de Lula, em 2009, também foi anunciada uma "reestruturação" na FUNAI, pretendendo garantir maior capacidade de atuação. Na verdade, essa reestruturação enxugou as sedes organizacionais do órgão indigenista, aumentando a quantidade de comunidades jurisdicionadas às Coordenações Regionais e sem aumentar os recursos financeiros e o número de profissionais capacitados para desenvolver projetos com os Povos Indígenas.

Com o Decreto 9.010/2017 (BRASIL, 2017) esse desmantelamento do Órgão Indigenista é ainda mais gritante. Foram sumariamente fechadas 51 Coordenações Técnicas Locais (CTLs), que representam as instâncias mais próximas dos Povos Indígenas, responsáveis pela área finalística do Órgão. Na sede do Órgão, em Brasília, a coordenação mais afetada foi a de Licenciamento Ambiental, sendo orquestrada uma facilitação para os grandes empreendimentos capitalistas nos territórios indígenas.

Vale ressaltar que essas ditas "reestruturações" foram bastante contestadas por vários povos indígenas que também reclamaram da falta de consulta prévia de acordo com a Convenção no 169 da OIT. 0 direito à autodeterminação dos povos indígenas - controlar suas vidas e suas terras continua a não ser garantido em nosso país. Além de ser o segmento mais pobre do Brasil, os indígenas estão excluídos das decisões que afetam os seus Territórios, muitas vezes causando impactos ambientais negativos, com prejuízos sociais, econômicos e culturais aos Povos Indígenas.

Após pouco mais de dois anos de um governo pífio exercido pelo então vice-presidente Michel Temer, as eleições de 2018 conduziram ao cargo de presidente o militar reformado Jair Bolsonaro, conhecido pela sua ignorância, prepotência e desprezo pelos direitos humanos mais elementares. Não por acaso, foi o próprio que, ao votar pelo impeachment da presidente Dilma, declamou sua veneração a um dos piores torturadores da época do regime militar, o coronel Carlos Brilhante Ustra.

Não nos cabe, neste espaço, tecer análises sobre os motivos da vitória eleitoral do segmento mais reacionário e protofascista em 2018, mas uma rápida retrospectiva desde então corrobora com o indiscutível quadro de exponencial retrocesso do país em torno das questões sociais, culturais, trabalhistas, educacionais e ambientais, cujo ônus recai, mais uma vez, sobre os ombros dos mais despossuídos, aí incluídos, naturalmente, os povos indígenas. Os dados são inegáveis: aumento do desemprego (agravado pela pandemia), recrudescimento da fome e da miséria, retrocesso dos direitos trabalhistas, sucateamento da saúde pública, desmonte dos programas assistenciais, devastação do meio ambiente, total desrespeito às minorias, entre tantos outros. 
Antes mesmo de eleito, o representante do Poder Executivo já fazia inúmeras declarações contrárias aos povos indígenas, tanto no que diz respeito aos seus direitos (não demarcação de terras indígenas e processo de "desmarcação" daquelas já homologadas), quanto também no fomento ao preconceito e discriminação. A concepção retrógrada do assimilacionismo e integracionismo, que permeou a história da política indigenista estatal e felizmente superada na Constituição de 1988, ganha novo destaque e defesa pelo governo federal em nosso país, o que demonstra um imenso retrocesso na abordagem do Estado brasileiro para com as populações indígenas.

Com o novo governo e uma política ultraliberal e com contornos fascistas, os ataques contra os povos indígenas se intensificam. Para além do desmantelamento total e paralisia do trabalho da FUNAI, com exonerações arbitrárias, perseguições a servidores e nomeações de militares para os cargos de chefia, o novo governo procura aniquilar aquilo que os povos indígenas brasileiros possuem de mais importante: o acesso coletivo e não capitalista à terra demarcada, fator fundamental para a manutenção das culturas e dos tradicionais modos de vida e organização social.

Apesar dos números apontarem que $12,4 \%$ do território nacional estão demarcados como terra indígena, isso não significa que a terra e os direitos dos índios estejam assegurados. A presença de posseiros, o mercado ilegal de mineração, o uso de pastagem e a falta de políticas públicas são constantes nos territórios indígenas. Por outro lado, várias comunidades indígenas continuam sem possuir o direito à terra, portanto, sem o direito de locais para morar, realizar suas atividades produtivas e praticar suas manifestações culturais.

Evidencia-se, cada vez mais, o propósito de incentivo às agressões ambientais, com o aumento do desmatamento, queimadas recordes, enfraquecimento das fiscalizações de órgãos como o Instituto Brasileiro do Meio Ambiente e dos Recursos Naturais Renováveis (IBAMA), desmantelamento da FUNAI, aumento significativo de invasões e ações de exploração ilegal de terras indígenas, seja através da grilagem, da exploração criminosa de madeira e da expansão de novos garimpos ilegais, assim como a expansão desordenada de áreas para produção agropecuária. Tudo isso acobertado ou mesmo incentivado pelo atual governo que tem como ministro do meio ambiente Ricardo Salles, um verdadeiro capataz dos segmentos mais retrógrados do empresariado rural.

A política do atual governo de favorecimento do agronegócio, com destruição ambiental e fomento à violência contra os territórios indígenas, deixa as suas populações em situação de grave vulnerabilidade social. 
Como já dito, a falta da terra para os Povos Indígenas acarreta prejuízos econômicos, sociais, ambientais e culturais, uma vez que a vida indígena está diretamente relacionada com a terra.

No entanto, para além da questão territorial, outros direitos sociais básicos também não têm sido cumpridos para os povos originários em nosso país. A educação e a saúde indígena continuam a possuir uma realidade bastante precária. A inexistência ou limitações de escolas nos territórios indígenas é ainda um obstáculo a ser superado, assim como o alto índice de analfabetos, principalmente entre os adultos e idosos. Estudantes indígenas buscam a continuidade dos seus estudos, porém, o ingresso nas Universidades públicas é difícil. Apesar do programa de cotas em algumas Universidades, a distância destas das suas Aldeias é quase um impeditivo, necessitando não só condições de acesso, mas também de políticas de permanência estudantil. Para além dessa questão, é necessário ir mais adiante na relação da educação e os Povos Indígenas. Não é suficiente apenas o ingresso de indígenas nas universidades. Torna-se necessário a transformação da lógica da universidade, incorporando os conhecimentos dos Povos Indígenas, as suas histórias e as suas lutas na perspectiva do ensino, pesquisa e extensão.

Os Povos Indígenas enfrentam grandes dificuldades no atendimento à saúde. Os índios apresentam os piores índices de saúde em todo o país, sofrendo com altas taxas de alcoolismo, suicídio, além do descaso e preconceito com que são tratados nos sistemas de saúde institucionais. A construção e reforma de Unidade Básica de Saúde nos territórios indígenas, com equipamentos adequados, consultório odontológico e regularidade de atendimento são demandas constantes. Para além dessas questões, a lógica de atendimento à saúde com os Povos Indígenas precisa ser transformada, atendendo aos princípios das especificidades do Sistema Único de Saúde (SUS), sendo necessária a incorporação das práticas, saberes e tradições que os indígenas utilizam na prevenção e tratamento de suas enfermidades. Além disso, o trabalho relacionado à saúde indígena não pode ser restrito ao tratamento de doenças, mas incorporar todas as condições necessárias para a sua vida social saudável, como moradia, educação, atividades produtivas, cultura, lazer, etc.

Em tempos da pandemia da COVID-19, essa situação fica ainda mais grave. A Secretaria Especial de Saúde Indígena (SESAI), responsável pela saúde específica e diferenciada aos Povos Indígenas, vem sendo sucateada de forma acentuada, não atendendo de maneira adequada o conjunto da população indígena em todo o território nacional. Registra-se ainda a subnotificação dos casos de doentes e óbitos de indígenas pela atual pande- 
mia, tendo em vista ser considerado apenas o Boletim Epidemiológico da SESAI, que não contempla a totalidade das populações indígenas em nosso país. Essa subnotificação agrava ainda mais o quadro de invisibilidade dos Povos Indígenas no país.

Além do cenário extremamente desfavorável, são frequentes os ataques institucionais contra os poucos direitos indígenas garantidos na Constituição. 0 parlamento de maioria conservadora e elitista, em especial a bancada ruralista com o apoio do poder executivo, vem fazendo constante pressão pela modificação de leis que tratam dos assuntos indígenas. São diversas iniciativas que buscam retirar os direitos territoriais dos povos indígenas e colocar os seus territórios a serviço do grande capital, permitindo os grandes empreendimentos, a mineração e o arrendamento de suas terras.

Dentre os ataques institucionais mais perversos, podemos citar pelo menos dois deles. 0 primeiro é a publicação da Instrução Normativa no 09 da Fundação Nacional do Índio, em abril de 2020 (FUNAI, 2020b). Através dessa instrução, o Órgão Indigenista se transforma em instância de certificação para a invasão de posseiros e grileiros no interior das Terras Indígenas. Ou seja, os invasores poderão requisitar documento à FUNAI para regularizar a sua invasão nos territórios indígenas, inclusive com licenciamento para o exercício de atividades econômicas de impacto ambiental, como extração de madeira. Registra-se que essa IN no 09/2020 está relacionada com a Medida Provisória 910/2019 (BRASIL, 2019), que busca avançar a grilagem em nosso país, podendo acarretar apropriação irregular de terra e conflitos fundiários de graves proporções. Não é à toa que essa MP é conhecida como "MP da grilagem" e prejudica frontalmente as populações tradicionais, provocando ainda maior concentração fundiária e desmatamentos, em especial na região da Amazônia.

0 segundo grande ataque institucional é a tese do Marco Temporal, através do Parecer 001/17 da Advocacia Geral da União - AGU (AGU, 2017). De acordo com esse Parecer, os indígenas só teriam direito ao processo de demarcação de suas terras caso estivessem na posse física desses territórios na data da promulgação da Constituição Federal de 1988, isto é, no dia 05 de outubro de 1988. Esse é um absurdo imenso, pois traz um caráter duplamente prejudicial aos povos indígenas: primeiro porque legaliza e legitima todas as violências praticadas contra os indígenas antes da promulgação da Constituição Federal de 1988, que foram responsáveis, na maioria das vezes, em expulsar os indígenas de seus territórios tradicionais; e segundo porque mantém a violência contra os povos indígenas, não 
lhes assegurando o direito territorial, que continuam tendo as suas terras usurpadas pelo grande capital.

Como se pode observar, são vários os desafios colocados aos povos indígenas na conjuntura atual. Apesar dos avanços constitucionais, a política indigenista oficial mantém práticas hegemônicas do poder tutelar, do assimilacionismo e o assistencialismo junto aos Povos Indígenas. $\mathrm{O}$ Estado brasileiro atua como intermediador entre as comunidades indígenas e outros segmentos da sociedade brasileira, autorizando ou não essas relações. Essa prática compromete à autogestão das Terras Indígenas, além de manter uma visão dos indígenas como seres "relativamente capazes".

Para além do regime tutelar, os seguidos governos neoliberais executaram e executam uma política de cooptação das lideranças indígenas, com o propósito de garantir o apoio aos governos através do pacto elitista de sociabilidade. Essa cooptação enfraquece os movimentos indígenas, que perdem a sua autonomia e independência política, ficando refém das políticas compensatórias e assistencialistas do Estado. Também acarreta no divisionismo das comunidades indígenas, fazendo com que diversos Povos disputem entre si as migalhas oferecidas pelo governo, perdendo o foco da resistência e luta contra a política indigenista oficial.

Por outro lado, existe mobilização, luta e resistência contra todo esse cenário. É imprescindível a mobilização e luta dos movimentos indígenas, indigenistas e de todas as forças progressistas, no sentido de frear os ataques contra os direitos indígenas, ao mesmo tempo em que é preciso avançar na construção de uma política indigenista, que tenha como princípio os indígenas como protagonistas nas tomadas de decisões.

\section{Mobilizações e bandeiras políticas}

Apesar das adversidades, o movimento indígena se organiza e mantém uma agenda de luta contra os ataques que estão sendo desferidos contra as suas populações e os seus territórios tradicionalmente ocupados.

O movimento indígena, através da Articulação dos Povos Indígenas do Brasil (APIB), realiza anualmente, no mês de abril, o Acampamento Terra Livre - ATL, reunindo organizações e lideranças indígenas de todo o país para discutir sobre a conjuntura nacional e construir as estratégias de luta e resistência. Apesar do cenário de pandemia pela COVID-19, a APIB realizou a 16a edição do ATL de maneira virtual em abril de 2020, sendo um importante momento de articulação e fortalecimento da luta do movimento indígena no Brasil (APIB, 2020). 
Outra vertente de atuação do movimento indígena tem sido a maior participação no processo eleitoral. Nas últimas eleições - ano 2020 - foram 2.216 candidaturas indígenas (prefeita/o, vice e vereador/a), 29\% a mais do que no pleito municipal passado. Ao final do processo eleitoral, teve-se 237 indígenas eleitos/as, entre prefeitos/as, vices e vereadores/as, o que representa $0,34 \%$ do total de eleitas/os no país, superior ao patamar de 0,26\% das eleições em 2016 (APIB, 2020). Apesar das limitações no âmbito da institucionalidade, esse aumento de participação indígena nas eleições indica um fortalecimento dos movimentos indígenas e uma maior ocupação dos espaços de luta para dar visibilidade às demandas e reivindicações dos povos originários.

Além do próprio movimento indígena, é importante também o papel de denúncia, propaganda e mobilização que algumas organizações indigenistas têm realizado nesse último período. Em nosso entendimento, a luta indígena não diz respeito somente aos índios, mas sim a todo o conjunto da sociedade brasileira, tendo em vista que representa a nossa história e é imensa a dívida que o país possui com essas populações.

Estamos convictos que as propostas dos povos indígenas na luta pelos seus direitos fundamentais devam ser elaboradas e encaminhadas pelos próprios indígenas, que mais do que ninguém sabem das suas reais necessidades como povos permanentemente ameaçados de invasão de suas terras ancestrais, expulsão de seus territórios e até de extermínio. A contribuição das organizações e dos/das militantes políticos deve ser, portanto, guiada prioritariamente por uma política de apoio às propostas de suas organizações autônomas e independentes, sejam elas de caráter étnico (local), interétnico, interlocal, regional ou nacional. Neste sentido propomos:

§ Demarcação / Homologação imediata de todas as terras indígenas no território nacional.

$\S$ Pela implementação imediata de políticas sociais dignas e diferenciadas aos Povos Indígenas, no que diz respeito à educação, saúde, moradia, lazer, dentre outras.

$\S$ Contras as obras capitalistas e neodesenvolvimentistas nos Territórios Indígenas, sem a Consulta Prévia e Informada, conforme previsto na Convenção 169 da OIT.

$\S$ Atualização do Estatuto do Índio com o protagonismo dos Povos Indígenas, superando os conceitos ainda vigentes de tutela, assimilação, integração e das políticas paternalistas e assistencialistas. 
$\S$ Contra os ataques institucionais que ferem os direitos indígenas, especial o Parecer 001/17 da Advocacia Geral da União (AGU).

$\S$ Construção de uma política indigenista estatal que rompa com o seu caráter repressivo e autoritário. Que seja construída em diálogo com as organizações indígenas e indigenistas e garanta a totalidade dos direitos territoriais, sociais e ambientais para todas as Terras Indígenas, bem como efetive um Plano de Carreira Indigenista para os servidores públicos, com condições adequadas de trabalho.

$\S$ Apesar da complexidade do assunto, devido, sobretudo, à diversidade das nações indígenas no país, consideramos ser importante a criação de uma articulação política nacional que funcione como interlocutor desses povos, algo como um Congresso Indígena Permanente, que reúna o maior número de representações dos povos indígenas.

$\S$ Instituir um grupo de trabalho reunindo representantes indígenas, parlamentares aliados e forças política de apoio para iniciar estudo sobre a instituição de um percentual de representação parlamentar dos povos indígenas, proposição a ser estendida a outras comunidades etnicamente diferenciadas, a exemplo dos ciganos e dos quilombolas.

\section{Referências}

APIB - Articulação dos Povos Indígenas do Brasil. Eleições 2020: número de indígenas eleitos é o maior da história do Brasil. APIBOFICIAL. [S.l.], 17 nov. 2020. Disponível em: <https://apiboficial.org/2020/11/17/eleicoes2020-em-contagem-parcial-apib-mapeia-159-candidatos-indigenaseleitos/>. Acesso em: 28 nov. 2020.

AGU, Advocacia Geral da União. Parecer nํ GMF-05 Parecer nํㅜ 0001/2017/GAB/CGU/AGU. Diário Oficial da União. Poder Executivo, Brasília, DF, 20 jul. 2017 , Edição: 138, Seção: 1, p. 7. Disponível em: <https://www.in.gov.br/web/dou/-/parecer-n-gmf-05-19185807>. Acesso em: 26 nov. 2020.

BRASIL. Constituição da República Federativa do Brasil (1988). Brasília: Senado, 1988.

. Lei no 3.071, de 1o de janeiro de 1916. Institui o Código Civil dos Estados Unidos do Brasil. Diário Oficial da União. Rio de Janeiro, RJ, 05 jan. 1916. Disponível em: <http://www.planalto.gov.br/ccivil_03/leis/ l3071.htm>. Acesso em: 03 nov. 2020 
BRASIL. Decreto no 5.484, de 27 de junho de 1928. Regula a situação dos índios nascidos no território nacional. Diário Oficial da União, seção 01, 14 jul. 1928, p. 17125. Disponível em: <https://www2.camara.leg.br/ legin/fed/decret/1920-1929/decreto-5484-27-junho-1928-562434norma-pl.html>. Acesso em: 03 nov. 2020.

Lei no 6.001, de 19 de dezembro de 1973. Dispõe sobre o Estatuto do Índio. Diário Oficial da União. Poder Executivo, Brasília, DF, 19 dez. 1973, Disponível em: <http://www.planalto.gov.br/CCivil_03/LEIS/L6001.htm>. Acesso em: 03 nov. 2020.

Decreto no 9.010, de 23 de março de 2017. Aprova a Estrutura Regimental e o Quadro Demonstrativo dos Cargos em Comissão e das Funções de Confiança do Conselho Administrativo de Defesa Econômica - CADE, remaneja cargos em comissão e funções de confiança e substitui cargos em comissão do Grupo-Direção e Assessoramento Superiores- DAS por Funções Comissionadas do Poder Executivo - FCPE. Diário Oficial da União. Poder Executivo, Brasília, DF, 24 mar. 2017, Ed. 58, Seção: 1 , p. 7. Disponível em: <https://www.in.gov.br/web/dou/-/decreto-n-9-011-de-23-demarco-de-2017-20121359>. Acesso em: 27 nov. 2020.

Medida Provisória no 910, de 10 de dezembro de 2019. Altera a Lei no 11.952, de 25 de junho de 2009, que dispõe sobre a regularização fundiária das ocupações incidentes em terras situadas em áreas da União, a Lei no 8.666, de 21 de junho de 1993, que institui normas para licitações e contratos da administração pública, e a Lei no 6.015, de 31 de dezembro de 1973, que dispõe sobre os registros públicos. Diário Oficial da União. Poder Executivo, Brasília, DF, 11 dez. 2019, ed. 239, Seção. 1 , p. 4. Disponível em: <https://www.in.gov.br/web/dou/-/medida-provisoria-n-910-de10-de-dezembro-de-2019-232671090>. Acesso em: 26 nov. 2020.

FAO - Organização das Nações Unidas para Alimentação e Agricultura. Pelo fim da fome e da pobreza para os povos indígenas da América Latina e do Caribe. Escritório Regional da FAO para a América Latina e o Caribe, 2018. Disponível em: <http://www.fao.org/americas/noticias/ver/pt/c/ 1106217/>. Acesso em: 28 nov. 2020.

FUNAI - Fundação Nacional do Índio. Quem são. Fundação Nacional do Índio. Brasília, 18 nov. 2020a, Atuação - povos indígenas. Disponível em: <https://www.gov.br/funai/pt-br/atuacao/povos-indigenas/quem-sao>. Acesso em: 28 nov. 2020. 
FUNAI - Fundação Nacional do Índio. Instrução Normativa no 09, de 16 de abril de 2020. Disciplina o requerimento, análise e emissão da Declaração de Reconhecimento de Limites em relação a imóveis privados. Diário Oficial da União. Poder Executivo, Brasília, DF, 22 abr. 2020b, ed. 76, Seção 1, p. 32. Disponível em: <https://www.in.gov.br/web/dou/-/instrucao-normativa-n-9-de-16-de-abril-de-2020-253343033>. Acesso em: $10 \mathrm{dez}$. 2020.

ISA. Instituto Socioambiental - Programa Povos Indígenas no Brasil. Serviço de Proteção aos Índios (SPI). Programa Povos Indígenas no Brasil, 2018. Disponível em: <https://pib.socioambiental.org/pt/Servi \%C3\%A7o_de_Prote\%C3\%A7\%C3\%A3o_aos_\%C3\%8Dndios_(SPI)>. Acesso em: 10 dez. 2020.

OIT. Convenção no 169 sobre povos indígenas e tribais e Resolução referente à ação da OIT. Organização Internacional do Trabalho. Brasília: OIT, 2011. 